\section{Commentary: Evolution of surgical technique in the hands of an expert}

\author{
Leora B. Balsam, MD
}

David and colleagues ${ }^{1}$ from Toronto provide an update on the team's single-surgeon series of patients with double valve (aortic and mitral) replacement and reconstruction of the fibrous skeleton of the heart. The approach used, which has been dubbed elsewhere "commando" or "UFO" due to a complexity that takes most surgeons out of their comfort zone, has been perfected over the years by Dr David. His early series was described in 1997 and included 43 patients. $^{2}$ A follow-up series was published in 2005 and included 73 patients. ${ }^{3}$ The current series, which spans a period of 35 years, includes 182 patients.

Reconstruction of the left-sided fibrous skeleton during combined aortic and mitral valve replacement is indicated in cases of infective endocarditis with paravalvular extension into the intervalvular fibrous body, which is also known as the aortomitral curtain or continuity. This occurs most often in cases of prosthetic valve endocarditis. It is also indicated during combined aortic and mitral valve replacement when there is extensive calcification of the intervalvular fibrous body and the adjacent valvular annuli. Additional indications include inadequate tissue to anchor the valve prostheses due to tissue loss or damage from prior valve replacement, or need for annular enlargement to avoid patient-prosthesis mismatch. David and colleagues ${ }^{1}$ series consists of $13 \%$ infective endocarditis cases, $34 \%$ extensive calcification cases (these cases also involve reconstruction of the posterior mitral annulus), 39\% inadequate tissue

\footnotetext{
From the Division of Cardiac Surgery, UMass Memorial Medical Center, Worcester, Mass.

Disclosures: The author reported no conflicts of interest.

The Journal policy requires editors and reviewers to disclose conflicts of interest and to decline handling or reviewing manuscripts for which they may have a conflict of interest. The editors and reviewers of this article have no conflicts of interest.

Received for publication Oct 15, 2021; revisions received Oct 15, 2021; accepted for publication Oct 15, 2021; available ahead of print Oct 20, 2021.

Address for reprints: Leora B. Balsam, MD, Division of Cardiac Surgery, UMass Memorial Medical Center, University Campus, 55 Lake Ave, N, Worcester, MA 01655 (E-mail: leora.balsam@umassmemorial.org).

J Thorac Cardiovasc Surg 2022;164:1485-6

$0022-5223 / \$ 36.00$

Copyright (C) 2021 by The American Association for Thoracic Surgery

https://doi.org/10.1016/j.jtcvs.2021.10.020
}

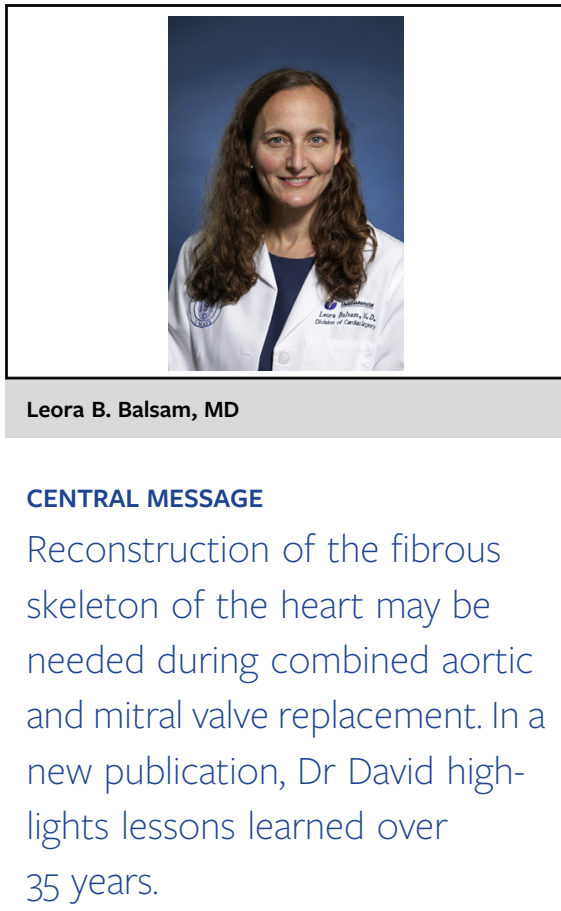

cases, and $13 \%$ patient-prosthesis mismatch cases. The majority of patients $(69 \%)$ had prior valve operations. Operative mortality was $13.2 \%$ and the median length of stay was 11 days. Implantation of a new pacemaker occurred in $33 \%$ of patients. Survival at 5 years was $69.4 \%$ and at 10 years was $51.1 \%$.

A small number of groups have reported their experience with similar procedures. ${ }^{4-6}$ Some of the differences in outcome likely relate to differences in preoperative patient characteristics (acuity and underlying disease process). David and colleagues ${ }^{1}$ make clear that there has been a learning curve in these series, and readers benefit from the technical lessons they share. Some salient points include how to create a tension-free patch reconstruction between the lateral and medial fibrous trigones, how to size and position the mitral valve prosthesis to avoid obstruction of the left ventricular outflow tract, preoperative imaging guidelines and intraoperative technique for posterior mitral annular reconstruction, and what patch materials to use and when. In regard to the latter point, the authors describe late calcification and fracture of bovine pericardial patch material that resulted in some cases of late valve dehiscence. For this reason, the team has moved toward using Dacron (DuPont, Wilmington, Del) patches in younger patients, although the ease of handling is less than with bovine pericardium. He also found that CorMatrix 
(CorMatrix Cardiovascular, Roswell, Ga) was not durable, and abandoned its use.

This series highlights the art of surgery in the hands of a master surgeon. Understanding the geometric relationships of intracardiac structures, having the willingness to learn from experience and adapt technique, and having tenacity in the face of technical challenges are absolute standout features. In an earlier report on the series, David and colleagues ${ }^{2}$ described a case requiring reconstruction of the entire mitral annulus due to calcification; the patient had 4 prior mitral valve replacements by other surgeons and developed early prosthetic valve endocarditis after the fifth (Dr David's) operation. The patient was offered a sixth operation, from which he eventually recovered. In the present series, $7.7 \%$ of patients underwent reoperation, which generally required taking down and reconstructing the patches and well as valve replacement. For those who are early in their career, this series offers a glimpse into the iterative process that Dr David has taken to become a surgical expert.

\section{References}

1. David TE, Lafreniere-Roula M, David CM, Issa H. Outcomes of combined aortic and mitral valve replacement with reconstruction of the fibrous skeleton of the heart. J Thorac Cardiovasc Surg. 2022;164:1474-84.

2. David TE, Kuo J, Armstrong S. Aortic and mitral valve replacement with reconstruction of the intervalvular fibrous body. J Thorac Cardiovasc Surg. 1997;114:766-72.

3. De Oliveira NC, David TE, Armstrong S, Ivanov J. Aortic and mitral valve replacement with reconstruction of the intervalvular fibrous body: an analysis of clinical outcomes. J Thorac Cardiovasc Surg. 2005;129:286-90.

4. Davierwala PM, Marin-Cuartas M, Misfeld M, Deo SV, Lehmann S, Garbade J, et al. Five-year outcomes following complex reconstructive surgery for infective endocarditis involving the intervalvular fibrous body. Eur J Cardiothorac Surg. 2020;58:1080-7.

5. Forteza A, Centeno J, Ospina V, Garcia Lunar I, Sanchez V, Perez E, et al. Outcomes in aortic and mitral valve replacement with intervalvular fibrous body reconstruction. Ann Thorac Surg. 2015;99:838-46.

6. Huuskonen A, Kaarne M, Vento A, Juvonen T, Raivio P. Outcomes of surgery for extensive infective endocarditis. J Card Surg. 2021;36:4675-81. https://doi.org/10. 1111/jocs. 16005
See Article page 1474 .

\section{Commentary: U can't touch this}

\section{Frank A. Baciewicz, Jr, MD}

Many times in his 1990 hit of the same name, MC Hammer intoned: "U can't touch this!"1 Readers might agree while reviewing Tirone David's 35-year experience with aorticmitral valve replacement and reconstruction of the intravalvular fibrous body. ${ }^{2}$ David and colleagues, ${ }^{3}$ who first described the procedure in 1997, detail the various iterations of the procedure, provide illustrations, and report 1-, 10 -, and 20 -year survival of $81.8 \%, 51.1 \%$, and $23.7 \%$, respectively.

The 13.2\% 30-day or in-hospital mortality is remarkable especially given that $69 \%$ of the operations were redo operations, with $16 \%$ being a third operation and $7 \%$

\footnotetext{
From the Michael and Marian Ilitch Department of Surgery, Wayne State University School of Medicine, Detroit, Mich.

Disclosures: The author reported no conflicts of interest.

The Journal policy requires editors and reviewers to disclose conflicts of interest and to decline handling or reviewing manuscripts for which they may have a conflict of interest. The editors and reviewers of this article have no conflicts of interest.

Received for publication Sept 11, 2021; revisions received Sept 11, 2021; accepted for publication Sept 13, 2021; available ahead of print Sept 16, 2021.

Address for reprints: Frank A. Baciewicz, Jr, MD, Michael and Marian Ilitch Department of Surgery, Wayne State University School of Medicine, Harper Hospital, 3990 John R St, Detroit, MI 48201 (E-mail: fbaciewi@dmc.org).

J Thorac Cardiovasc Surg 2022;164:1486-7

0022-5223/\$36.00

Copyright (c) 2021 by The American Association for Thoracic Surgery

https://doi.org/10.1016/j.jtcvs.2021.09.022
}

Check for updates

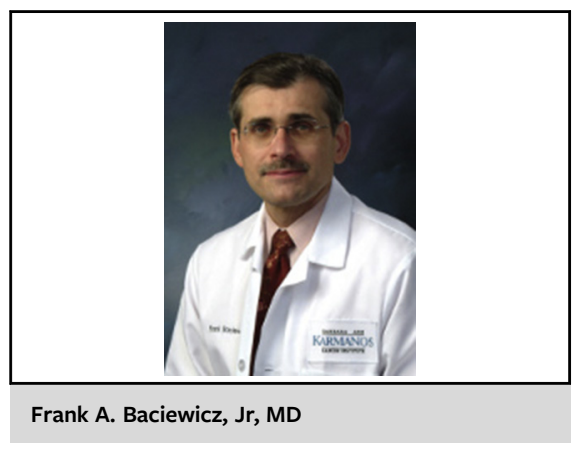

CENTRAL MESSAGE

The pioneer of aortic/mitra

replacement and reconstruction

of the intravalvular fibrosa pre-

sents his 35-year experience with

outstanding 30-day and long-

term outcomes.

being a fourth operation. I assume the later in the re-do sequence, the greater the risk. In addition, 39\% had previous aortic root/valve and mitral valve replacement, although previous aortic root replacement did not increase 30-day mortality. 